\title{
ON THE (NONMONOTONIC) RELATION BETWEEN ECONOMIC GROWTH AND FINANCE
}

\author{
Alberto Bucci \\ University of Milan \\ Simone Marsiglio \\ University of Wollongong
}

\section{Catherine Prettaner}

\section{Statistics Austria}

and

Vienna University of Economics and Business

\begin{abstract}
We analyze the simplest possible model of endogenous growth to account for the role of financial development. In our setting, financial development affects productivity and determines the amount of resources subtracted to capital investment. We show that under very general assumptions, the relation between economic growth and financial depth is nonmonotonic, and eventually bell-shaped. We empirically assess our results in a framework that allows to distinguish between long-run and short-run effects. We establish a cointegrating relation and derive the long-run elasticities of per capita gross domestic product (GDP) with respect to employment, the physical capital stock, and financial depth-relying on linear as well as nonlinear models for the finance-growth nexus. We employ the results of the first step estimation to specify an error-correction model and find that there is strong evidence for a nonlinear relationship between financial depth and per capita GDP, consistently with what was predicted by our theoretical model.
\end{abstract}

Keywords: Economic Growth, Financial Depth, Financial Development

\section{INTRODUCTION}

The recent global financial crisis has radically changed our understanding of the way financial markets impact on the real economy. While the seminal work by King and Levine (1993a) has motivated the largely shared view that banks and financial markets provide important services to the economy and thereby foster economic growth in the long run [see Levine (2005), for an overview], this perception has to

\footnotetext{
We are indebted to an anonymous referee for valuable comments and suggestions. We also wish to thank the participants in the conference "Economics, Economic Policies and Sustainable Growth in the Wake of the Crisis" [Ancona (2016)] for insightful discussions. All remaining errors and omissions are our own sole responsibility. Address correspondence to: Simone Marsiglio, School of Accounting, Economics and Finance, University of Wollongong, Northfields Avenue, Wollongong 2522 NSW, Australia; e-mail: simonem@uow.edu.au.
} 
be reconsidered in face of recent developments. With the spillover of the financial turmoil to the real economy in the second half of 2008, the public, political, and academic discussion on this subject matter has changed substantially. Overall, it is now widely recognized that although finance provides important services to the economy, the growth of the financial sector per se has contributed to the most severe financial crisis since the great depression, threatening the prospects of future economic growth. In particular, the recent global financial crisis has stressed more than ever that the same mechanisms through which finance helps economic growth can also make finance a source of economy wide fragility and crisis [Beck (2013)]. Indeed, even if finance is supposed to alleviate information asymmetries and agency problems between savers and entrepreneurs, it also generates conflicts of interest between depositors or creditors and banks. The potential growth-enhancing effect of finance on the real economy thus constitutes at the same time a source of instability with potential repercussions on the real economy ${ }^{1}$ [Beck (2012)].

Despite its potentially relevant role on long-term economic outcomes and the huge body of empirical studies, very few have been thus far the theoretical works trying to analyze in depth the possible channels relating financial development and economic growth. Indeed, after Pagano's (1993) seminal paper, which has first pointed out the variety of mechanisms through which finance might impact on economic growth, the theoretical literature has especially focused on the effects of financial intermediation on human capital [De Gregorio (1996), De Gregorio and Kim (2000), Bucci and Marsiglio (2018)], technological progress [Morales (2003), Trew (2008)], and more recently physical capital accumulation [Trew (2014), Bucci and Marsiglio (2018)]. The existence of such a variety of channels to eventually account for suggests that from an empirical point of view understanding the sign of the growth and finance nexus is all but simple. Traditionally finance is quantified in terms of financial depth, and empirical evidence in this context is mixed: often finance is found to be positively related to economic growth [Boyd and Prescott (1986), Allen (1990), Greenwood and Jovanovic (1990)], but equally often the relation is also found to be negative [Allen et al. $(2009,2014)]$. The most recent evidence explains such ambiguous results by identifying the existence of a nonlinear and nonmonotonic relationship between economic growth and finance [Cecchetti and Kharroubi (2012), Law and Singh (2014), Arcand et al. (2015)]. Specifically, at lower levels of financial depth, economic growth is found to be positively associated with finance, while at higher levels, growth and finance seem to be negatively related with each other, suggesting thus that while in earlier phases of economic development finance is growth enhancing at later stages too much finance might ultimately harm economic growth. Overall, the growth and finance relation is, thus, likely to be bell-shaped, meaning that there might exist a threshold value above/below which the sign of the relation changes. To the best of our knowledge, among theoretical works, only the work of Bucci and Marsiglio (2018) is able to explain why such a nonmonotonic relation might take place. Using a two-sector endogenous growth model, their argument is based on the presence of a tension between creation and obsolescence effects induced by more 
finance on human capital accumulation. The goal of the present paper is to further contribute to this scant theoretical literature by showing how naturally such a nonmonotonicity can arise even in the simplest possible one-sector endogenous growth setup, and to provide an empirical validation for our conclusions.

This paper proceeds as follows. Section 2 introduces our analytical framework, namely, a finance-extended AK model. Financial development plays a twofold role in our setup, as it affects both total factor productivity and the amount of resources subtracted to capital accumulation; these two effects jointly determine how financial depth and economic growth are ultimately related. We analyze under which conditions there may exist a nonmonotonic relationship between economic growth and finance. In particular, we show that in the most realistic scenario (that is, the productivity effect dominating at lower levels of financial development and the crowding out effect dominating at higher levels), the growth and finance relation will take an inverted- $U$ shape, exactly as suggested by recent empirical evidence. In Section 3, we empirically assess our theoretical results by using a framework that allows a distinction between short-run and long-run effects in order to evaluate how how finance affects output and growth. Our dataset contains information on 44 developed and developing countries over the period 19952011. We establish a cointegrating relation and derive the long-run elasticities of per capita GDP with respect to employment, physical capital, and financial depth, relying on linear as well as nonlinear models for the finance-growth nexus. We employ the results of the first step estimation to specify an error-correction model in order to distinguish between eventual short-run and long-run effects of finance on economic growth. The empirical results obtained strongly support our theory: there is a strong evidence for a nonlinear relationship between financial depth and per-capita GDP. As usual, Section 4 presents some concluding remarks. Additional information about the empirical analysis including some robustness checks is presented in Appendices A-C.

\section{A SIMPLE THEORETICAL MODEL}

The framework is an extended AK-type endogenous growth model that allows for a role of financial development. We assume that the degree of financial development is measured by a parameter, $\phi>0$, which (exogenously) increases over time. This means that we do not try to explain financial development per se, but we simply analyze its implications on the growth and finance relation provided that it does occur. In our framework, financial development affects both the total factor productivity and the amount of resources subtracted to capital investment. These two effects formalize, respectively, the fact that financial intermediaries allow to channel resources to the most efficient uses [Pagano (1993), Trew (2008), Bucci and Marsiglio (2018)], and the fact that financial intermediation is a costly activity draining resources away from capital accumulation [Pagano (1993), Trew (2014) Bucci and Marsiglio (2018)]. Therefore, the resources subtracted to capital accumulation determine the level of financial intermediation. 
The social planner seeks to maximize the social welfare subject to the economic and financial constraints, by choosing the level of consumption, $c_{t}$. We abstract from population growth and the population size is normalized to unity for the sake of simplicity; we thus state the problem directly in per capita terms. Social welfare is the infinite discounted ( $\rho>0$ is the pure rate of time preference) sum of the instantaneous utilities; the utility function is assumed to be isoelastic, $u\left(c_{t}\right)=\frac{c_{t}^{1-\sigma}-1}{1-\sigma}$, with $\sigma>1$ representing the inverse of the intertemporal elasticity of substitution. The economy produces a unique consumption good, $y_{t}$, according to a linear production function $y_{t}=\tilde{A} k_{t}$, where $k_{t}$ denotes capital and $\tilde{A}$ is the total factor productivity, a measure of the available level of technology. We postulate that the total factor productivity depends on the degree of financial development $\phi$, that is, $\tilde{A}=A(\phi)$; since financial development is thought to play a positive role in boosting research and development $(\mathrm{R} \& \mathrm{D})$ activity and technical change, ${ }^{2}$ we assume that $A^{\prime}>0$. We also assume that the degree of financial development determines how many resources are subtracted to capital investment (capital crowding out), and specifically a certain share $0<\xi(\phi)<1$ of output is used for financial activities ${ }^{3}$; in order to keep the analysis in principle as much general as possible, and because we are agnostic about the real impact of financial development on the efficiency of financial activities, we do allow for $\xi^{\prime} \gtreqless 0$. The accumulation of capital is thus given by $\dot{k}_{t}=[1-\xi(\phi)] y_{t}-\delta k_{t}-c_{t}$, where $\delta>0$ represents the capital depreciation rate. The amount of resources subtracted to capital accumulation by the financial activities determines the level of financial intermediation, $f_{t}=\xi(\phi) y_{t}$. Therefore, financial depth $d_{t}=\frac{f_{t}}{y_{t}}$ directly depends on the degree of financial development $d_{t}=\xi(\phi)$. Given the initial conditions for capital, $k_{0}>0$, the planner's problem can be summarizes as follows:

$$
\begin{aligned}
\max _{c_{t}} \quad W & =\int_{0}^{\infty} \frac{c_{t}^{1-\sigma}-1}{1-\sigma} e^{-\rho t} d t . \\
\text { s.t. } & \dot{k}_{t}=[1-\xi(\phi)] A(\phi) k_{t}-\delta k_{t}-c_{t} . \\
d_{t} & =\xi(\phi) .
\end{aligned}
$$

First-order necessary and sufficient conditions straightforwardly lead to the characterization of the balanced growth path (BGP) equilibrium, along which all variables grow at constant rates. Along the BGP, the common economic growth rate, $\gamma \equiv \gamma_{c}=\gamma_{k}=\gamma_{y}$ and financial depth are given by the following expressions, respectively:

$$
\begin{aligned}
\gamma & =\frac{[1-\xi(\phi)] A(\phi)-\delta-\rho}{\sigma}, \\
d_{t} & =\xi(\phi) .
\end{aligned}
$$

As usual in any AK-type growth framework, provided that some parameter restrictions hold, that is $[1-\xi(\phi)] A(\phi)>\delta+\rho$, meaning that the net (of 
the financial's sector absorption of resources) total factor productivity is large enough, the BGP is well defined, and the economic growth rate is strictly positive. Note that financial development affects economic growth in a twofold way, namely, through a productivity, $A(\phi)$, and a capital crowding-out, $\xi(\phi)$, effect. Therefore, the sign (and eventually the size) of the productivity and crowding-out effects ultimately determines how economic growth depends on financial development. Indeed, simple differentiation of the above expressions straightforwardly yields

$$
\begin{aligned}
\frac{\partial \gamma}{\partial \phi} & =\frac{[1-\xi(\phi)] A^{\prime}(\phi)-\xi^{\prime}(\phi) A(\phi)}{\sigma} \\
\frac{\partial d_{t}}{\partial \phi} & =\xi^{\prime}(\phi) .
\end{aligned}
$$

In the last few years, and as a consequence of financial development, the size of the financial sector has in many countries (especially the most industrialized ones) grown faster than GDP, implying that financial depth has consistently increased. In terms of our setting, this leads us to postulate that $\xi^{\prime}>0$. Under such an assumption, the relationship between financial development and economic growth may be nonmonotonic, and in particular it could resemble an inverted- $U$ whenever the productivity effect dominates at lower levels of financial development while the crowding out effect dominates at higher levels. Whenever this happens, by plotting economic growth versus financial depth, it is possible to realize that the overall relation between economic growth and financial depth may be bellshaped, consistently with empirical evidence. In the less likely case in which financial depth falls with financial development, that is, $\xi^{\prime}<0$, the relation between economic growth and financial depth is monotonic (and unambiguously positive). This allows us to state the following result.

PROPOSITION 1. The sign of the relation between the capital crowding-out effect and financial development determines the nature of the growth and finance nexus. Only if the crowding-out effect rises with financial development there might exist a nonmonotonic relation between economic growth and financial depth.

Proposition 1 shows that even in the simplest setup (that is, the one-sector AK growth model), the relation between finance and economic growth may be nonmonotonic, and whether this is likely to happen or not crucially depends on how financial development affects the crowding-out effect. In the most realistic framework, in which financial depth rises with financial development the result arises almost naturally from the tension between the productivity and the crowdingout effects. We now proceed with a trivial example to further emphasize how the existence of a bell-shaped economic growth and finance relation seems to be a natural outcome in a simple capital accumulation context, and does not even require any ad-hoc assumption about the shape of the two forces in place (i.e., the productivity and crowding-out functions, respectively). 
Example 1. Assume that $A(\phi)=A \phi$ and $\xi(\phi)=\xi \phi$ with $A>0$ and $\xi>0$, meaning that both the productivity and crowding out effects are linear functions of financial development, $\phi$. The sign of the economic growth and financial development relation is given by $\frac{\partial \gamma}{\partial \phi}=\frac{A(1-2 \xi \phi)}{\sigma}$, meaning that $\phi=\frac{1}{2 \xi}>0$ represents the threshold value below (above) which the relation is positive (negative), and thus $d_{t}=\frac{1}{2}$ is the growth-maximizing level of financial depth.

To the best of our knowledge the only work providing some theoretical explanation for the presence of an inverted- $U$ shaped relationship between economic growth and finance is Bucci and Marsiglio's (2018). However, differently from their human capital-driven, two-sector, endogenous growth model in which some nonlinearity in (at least one of) the effects that determine the sign of the growthfinance relation is needed to eventually generate a nonmonotonic association between the two variables, in our framework even linear productivity and crowding-out functions are enough to give rise to the result. This confirms that ad-hoc assumptions about the shape of some particular function is not needed in order to eventually generate a bell-shaped growth-finance relation in our one-sector endogenous growth framework.

In order to better understand the conclusions of our stylized model, it is critical to emphasize what exactly is financial development, which is conceptually different from financial depth. In our setting, financial development $\phi$ affects both the productivity and the level of capital crowding out. Among other possible interpretations of financial development [see Cihak et al. (2012), for a discussion of the several dimensions that the financial development may refer to], probably the most appropriate to capture our model's formulation is represented by the size of the financial sector. Indeed, an expansion of the financial sector's size brings about exactly the two effects that our model aims to capture. On the one hand, with a larger financial sector, it is easier to build a network of financial intermediaries capable to screen and monitor more deeply firms' activities in such a way that available funds are channeled solely toward the most productive uses, which ultimately leads to an increase in the total factor productivity. On the other hand, a larger financial sector can also lead more easily to inefficiencies of the industry as a whole; such an increase in the financial sector's inefficiencies takes the form in our model of a larger amount of resources subtracted to capital investments. This is consistent with our results (see Proposition 1) that are derived exactly in a setting where $A^{\prime}>0$ and $\xi^{\prime}>0$; whenever this is the case the relation between growth and financial depth turns out to be nonmonotonic, as suggested by the most recent empirical evidence.

\section{EMPIRICAL ASSESSMENT}

While it is commonly agreed that the financial system provides different services to the economy, it is more debated how to effectively measure all these 
services altogether. Moreover, financial development comprises a wide array of activities or improvements in the way financial services are provided to end-users, therefore, it is difficult to find one single measure to capture all such features. Indeed, financial development is a complex concept, defined along many different dimensions, such as size, access, stability, and efficiency [Cihak et al. (2012)]. As a result, most empirical applications aiming to analyze the relation between growth and financial development identify some indicator, which may capture one of these dimensions only; the preferred one is generally represented by financial depth, since it can be easily defined and identified as the size of the financial sector relative to the economy. In order to test from an empirical point of view, the implications of our previous analysis we shall take a similar approach and focus mainly on how financial depth affects the economy.

Specifically, from our theoretical analysis, we have seen that as long as financial development positively affects both the productivity and the size of the financial sector, the relation between growth and financial depth will be nonmonotonic, independently of the specific shape of the productivity and the crowding-out functions. In order to proceed with an empirical validation of our conclusions, in the following, we shall assume that such functions take the simplest possible form, that is they increase linearly with the degree of financial development (as in our Example 1). Specifically, we assume that $A(\phi)=A \phi$ and $\xi(\phi)=\xi \phi$, which implies that $d_{t}=\xi \phi$ and $y_{t}=\frac{A}{\xi} d_{t} k_{t}$; this allows us to implement a straightforward estimation approach to focus on how financial depth (measured by private credit out of GDP) affects output, which is consistent with what is traditionally done in the empirical literature. We shall later extend the analysis to consider other proxies for financial activities, showing that our main qualitative results will remain unchanged (see Appendix C).

Differently from our theoretical analysis, in the empirical assessment, we shall not focus only on the long-run relation between growth and finance (implicitly assumed in the AK formulation of the production function) but we allow also for short-run effects. As it has been shown in several time series applications [e.g., Christopoulos and Tsionas (2004), Wu et al (2010)], it is important not only to consider the cross-sectional dimension of the finance and growth nexus but to also take into account the time series dimension. The time series given in the production function $y_{t}=\frac{A}{\xi} d_{t} k_{t}$ are usually found to contain unit roots and are likely to be cointegrated. This calls for testing for cointegration and if present, applying an empirical model that makes use of the joint information on shortrun and long-run dynamics, which is entailed in the series. The derivation of the finance and growth nexus as presented in Section 2 would then be interpreted as the long-run relationship surrounded by short-run fluctuations and dynamic adjustment to equilibrium. When identifying the cointegrating relation in the first step, the model is written in levels rather than in growth rates. The second step embeds the results from the first step in an error-correction model, which captures growth rates. 
We thus consider a more general Cobb-Douglas production function depending also on labor, $N_{t}$, as follows: $Y_{t}=\left(\frac{A}{\xi} d_{t}\right)^{\eta} K_{t}^{\alpha} N_{t}^{\tilde{\beta}}$, where capital letters denote aggregate variables. More specifically, for the empirical longrun model, we regress total income of country $i$ in period $t,\left(Y_{i t}\right)$, against the physical capital stock $\left(K_{i t}\right)$, labor input $\left(N_{i t}\right)$, and a measure of financial depth $\left(\mathrm{FD}_{i t}\right)$. Hence, the basic empirical model for the long-run relationship reads as follows:

$$
\ln y_{i t}=a+\alpha \ln K_{i t}+\beta \ln N_{i t}+\eta \ln \mathrm{FD}_{i t}+\epsilon_{i t},
$$

where we use per capita GDP, $y_{i t}$, as measure of output per capita, such that $\alpha$ is the elasticity of per capita GDP with respect to the capital stock, $\eta$ is the elasticity of per capita GDP with respect to the financial depth indicator (here, private credit over GDP) and $\beta=\tilde{\beta}-1$ is the elasticity of per capita GDP with respect to total employment, and $a$ is a constant term. For total income $Y_{i t}$, we use GDP at constant 2005 USD, for labor $N_{i t}$ total employment, and we employ data on the physical capital stock provided by Berlemann and Wesselhoeft (2014). All variables except the physical capital stock stem from the World Development Indicators Database. We employ domestic credit to the private sector as percentage of GDP as a measure of financial depth as this allows us to compare our results to previous studies and delivers a comparatively long-time series dimension. We work with a broad sample of 44 developed and developing countries over the period 1995-2011, which yields a high degree of variation in the data (for a list of countries see Appendix A).

In order to evaluate the time series of the variables, we conduct a series of panel unit root and cointegration tests, reported in Table B.1 in appendix B. We employ the Levin et al. (LLC, 2002), Breitung (2005), and Im et al. (IPS, 2003) panel unit root tests to check for stationarity in the data. The results of these tests strongly indicate that per capita GDP, employment, and private credit are all integrated of order one. To examine whether the time series are cointegrated, we perform the Pedroni $(1999,2004)$ residual-based cointegration test. The results support the hypothesis of a long-run equilibrium cointegrating relationship among per capita GDP, the physical capital stock, employment, and private credit. In the conceptional world of cointegration, this means that even though there may be deviations from equation (8) in the short run, they should not have a permanent impact but lead to an adjustment process that maintains the economy close to this relationship in the longer term. As shown in Section 2, this relationship is likely to be nonmonotonic, and we hence have to consider these possible nonlinearities in the identification of the long-run relationship.

\subsection{Identifying the Long-Run Relationship}

We employ the dynamic ordinary least squares (DOLS) estimator put forward by Saikkonen (1991) for estimating the cointegrating relation in a panel as it delivers 
TABLE 1. Long-run relationship: Linear model

\begin{tabular}{lcccc}
\hline & $\ln N$ & $\ln K$ & $\ln$ FD & Obs \\
\hline 1) DOLS estimator & $0.3660^{* * *}$ & $0.3041^{* * *}$ & $0.1611^{* * *}$ & 490 \\
Country FE & $(0.0685)$ & $(0.0386)$ & $(0.0111)$ & \\
2) DOLS estimator & 0.0191 & $0.1170^{* * *}$ & $0.0856^{* * *}$ & 490 \\
Country and period FE & $(0.0719)$ & $(0.0405)$ & $(0.0127)$ & \\
\hline
\end{tabular}

Dependent variable is $\ln y_{i t}$.

Heteroskedasticity robust standard errors in parentheses.

${ }^{* * * *}\left({ }^{* *}\right)\left[{ }^{*}\right]$ indicates significance at the $1 \%(5 \%)[10 \%]$, respectively.

unbiased and asymptotically efficient estimates of the coefficients in (8) when confronted with possible endogeneity among the variables. As shown by Wagner and Hlouskova (2010), this estimator outperforms the other estimators such as the fully modified OLS estimator in panels where the time series dimension is relatively short.

As a baseline and in order to compare our results to previous works that assume a linear finance and growth nexus, we first estimate a simple linear model, with country fixed effects and with country- and period-fixed effects. The estimated long-run elasticities are presented in Table 1 . When including only country fixed effects, the elasticities of per capita GDP with respect to employment and the capital stock are $37 \%$ and $30 \%$, both highly significant. The elasticity of financial depth is also positive and estimated to be $16 \%$, which is also highly significant. With country- and period-fixed effects, the effect of employment on per capita GDP is estimated to be close to zero, while the elasticities of the capital stock and financial depth are now estimated to be half as strong but still significantly positive at $12 \%$ and $9 \%$. From this first look at the long-run relationship, where we assume a homogeneous relationship for all countries, we would conclude that there is a positive and significant effect of financial depth on GDP, when measured with private credit. Estimating a linear model does confirm the results of King and Levine (1993a, 1993b), Levine and Zervos (1998), Levine et al. (2000), Beck et al. (2000), Benhabib and Spiegel (2000), and many others of a positive finance growth nexus. In the next step, we wish to check whether the results are robust to the introduction of a nonlinear relationship between finance and growth.

As suggested by our theoretical framework and as demonstrated in recent empirical works, the nexus between financial depth and growth might come from a nonlinear relationship, where the effect of finance on growth depends on the achieved level of financial depth or income. We therefore estimate the following threshold model, where the thresholds are chosen by rolling estimation windows with a minimum of $10 \%$ of observations in each regime and according to the model with the lowest sum of squared residuals (SSR). More specifically, we estimate 
the model

$$
\begin{aligned}
& \ln y_{i t}=a+\alpha \ln K_{i t}+\beta \ln N_{i t}+\eta_{\tau_{1}} \ln \mathrm{FD}_{i t} * I_{\tau_{1}}+\eta_{\tau_{2}} \ln \mathrm{FD}_{i t} * I_{\tau_{2}} \\
& +\eta_{\tau_{3}} \ln \mathrm{FD}_{i t} * I_{\tau_{3}}+\sum_{j=-k}^{k} \theta_{1, i j} \Delta \ln K_{i t-j}+\sum_{j=-k}^{k} \theta_{2, i j} \Delta \ln N_{i t-j} \\
& +\sum_{j=-k}^{k} \theta_{3, i j} \Delta \ln \mathrm{FD}_{i t-j}+u_{i t},
\end{aligned}
$$

where $I_{\tau_{1}}$ defines the regime covering all countries with an average credit to GDP level below the $\tau_{1}$ th-quantile and $\tau_{1}=10, \ldots, 89$. The second regime is defined accordingly with the average credit to GDP being above the $\tau_{1}$ th-quantile and below the $\tau_{2}$ th-quantile, which runs from $\tau_{2}=\tau_{1}+10, \ldots, 99$. The third regime covers all countries with the average credit to GDP above the $\tau_{2}$ th-quantile. We estimate the model with country fixed effects and with country- and periodfixed effects and choose the best model according to the SSR - and thereby the thresholds which determine the regimes. For the model with country- and periodfixed effects, we end up with a model where the first regime is defined by a threshold covering all observations below the 12th quantile, the second regime by the following $37 \%$ of observations, and the third regime applying to countries with an average financial depth indicator above the 49th quantile.

The results of the threshold model, reported in Table 2 , clearly show a nonmonotonic inverted $U$-shaped relationship between finance and growth in the long run. Credit to GDP becomes less beneficial for per capita GDP at higher levels of financial depth and the effect of private credit on GDP eventually becomes negative. While the impact of credit on GDP is large in the lowest regime, a $1 \%$ higher credit to GDP share is associated with $30 \%$ increase in per capita GDP; this effect is not even half as strong in the second regime and insignificant in third. When country- and period-fixed effects are included, the effect is strong in the first regime, decreases to one-third of the initial effect for higher levels of credit and becomes negative in the third regime.

\subsection{Error-Correction Model}

To examine the short-run and long-run effect of finance on growth, we make use of the integration and cointegration properties of the data and specify an error-correction model. We construct the error-correction term using the long-run elasticities of per capita GDP with respect to employment, the physical capital stock, and financial depth, which we have gained earlier. The basic error-correction model reads as follows:

$$
\begin{aligned}
& \Delta \ln y_{i t}=b_{0}+b_{1} \Delta \ln y_{i t-1}+b_{2} \Delta \ln N_{i t-1}+b_{3} \Delta \ln K_{i t-1} \\
& \quad+b_{4} \Delta \ln \mathrm{FD}_{i t-1},+\theta \mathrm{EC}_{t-1}+\epsilon_{i t}
\end{aligned}
$$


TABLE 2. Long-run relationship: Threshold model

\begin{tabular}{|c|c|c|c|c|c|c|}
\hline $\ln N$ & $\ln K$ & $\begin{array}{c}\ln \mathrm{FD} \\
\text { Regime } 1\end{array}$ & $\begin{array}{c}\text { ln FD } \\
\text { Regime } 2\end{array}$ & $\begin{array}{c}\ln \mathrm{FD} \\
\text { Regime } 3\end{array}$ & $R^{2}$ & Obs \\
\hline \multicolumn{7}{|c|}{ With country-fixed effects } \\
\hline $\begin{array}{c}0.1732^{* *} \\
(0.0848)\end{array}$ & $\begin{array}{l}0.4857^{\text {*** }} \\
(0.0522)\end{array}$ & $\begin{array}{l}0.2982^{* * *} \\
(0.0207)\end{array}$ & $\begin{array}{l}0.1150^{* * *} \\
(0.0175)\end{array}$ & $\begin{array}{c}0.0000 \\
(0.0156)\end{array}$ & 0.999 & 490 \\
\hline \multicolumn{7}{|c|}{ With country- and period-fixed effects } \\
\hline $\begin{array}{c}-0.0844 \\
(0.0788)\end{array}$ & $\begin{array}{l}0.3133^{* * *} \\
(0.0609)\end{array}$ & $\begin{array}{l}0.2189^{* * *} \\
(0.0192)\end{array}$ & $\begin{array}{l}0.0700^{* * *} \\
(0.0145)\end{array}$ & $\begin{array}{c}-0.0698^{* * *} \\
(0.0147)\end{array}$ & 0.999 & 490 \\
\hline
\end{tabular}

Dependent variable is $\ln y_{i t}$.

Heteroskedasticity robust standard errors in parentheses.

${ }^{* * *}\left({ }^{* *}\right)\left[^{*}\right]$ indicates significance at the $1 \%(5 \%)[10 \%]$, respectively.

where the error-correction term $\mathrm{EC}_{t}$ reflects the deviations from equilibrium such that $\mathrm{EC}_{t}=\ln y_{i t}-\left(\hat{\alpha} \ln K_{i t}+\hat{\beta} \ln N_{i t}+\hat{\eta} \ln \mathrm{FD}_{i t}\right)$. A significant (negative) error-correction coefficient, $\theta$, implies long-run causality, which is "equilibrium enforcing" in the sense that a deviation from the long-run equilibrium triggers an automatic adjustment back to equilibrium and $\theta$ measures the speed of adjustment to the long-run equilibrium. If we can reject the null hypothesis that $\theta=0$, then this is a strong indication of a long-run causal effect of finance (private credit) on growth.

In order to use the estimates from equation (8) for the construction of the errorcorrection term, we have to ensure that the error-correction term (which reflects the deviations from equilibrium) is stationary. Testing the error-correction term in the linear model for unit roots yields, however, mixed results. For the whole sample period, both the LLC test and the IPS test cannot reject the null hypothesis of a common unit root when no trend is included in the Dickey-Fuller equation. If a trend is included, the LLC test rejects, while the IPS test does not. We can, however, reject the unit root hypothesis in both tests when we cut off the sample at the start of the global crisis and run the test for the sample 1995-2009 and include a trend. For the error-correction term including country- and period-fixed effects, only the LLC test rejects. Looking at the error-correction term based on the nonlinear model, the LLC test rejects in the model with trend as well as in the model without a trend, when the years of crisis are excluded. Also, for the errorcorrection term based on the model with country- and period-fixed effects, both tests now reject, if we exclude the crisis. The unit root tests on the error-correction terms therefore support the use of a nonlinear model rather than a linear model.

The results of the basic error-correction model when based on a linear long-run relationship are presented in Table 3. We find that, while the DOLS estimation showed the positive long-run relationship of per capita GDP and financial depth, this positive relationship does not hold in the short run. First, there is no statistically significant short-run effect of financial depth on GDP. This is to be expected, as 
TABLE 3. Error-correction model

\begin{tabular}{lcccc}
\hline & \multicolumn{4}{c}{ Effects in cointegrating regression } \\
\cline { 2 - 5 } & \multicolumn{2}{c}{ Country FE } & Country and period FE \\
\hline \multirow{2}{*}{$\Delta \ln y(-1)$} & $0.1946^{* * *}$ & $0.2724^{* * *}$ & $0.1952^{* * *}$ & $0.2729^{* * *}$ \\
& $(0.0728)$ & $(0.0730)$ & $(0.0728)$ & $(0.0728)$ \\
$\Delta \ln N(-1)$ & 0.0678 & 0.1577 & 0.0639 & 0.1549 \\
& $(0.0850)$ & $(0.0755)$ & $(0.0853)$ & $(0.0766)$ \\
$\Delta \ln K(-1)$ & $-0.6071^{* * *}$ & $-0.3860^{* * *}$ & $-0.6170^{* * *}$ & $-0.3951^{* * *}$ \\
& $(0.1467)$ & $(0.1261)$ & $(0.1470)$ & $(0.1267)$ \\
$\Delta \ln \mathrm{FD}(-1)$ & 0.0055 & 0.0026 & 0.0041 & 0.0016 \\
& $(0.0080)$ & $(0.0063)$ & $(0.0086)$ & $(0.0068)$ \\
EC term & $-0.0549^{*}$ & $-0.0467^{*}$ & $-0.0584^{*}$ & $-0.0489^{*}$ \\
& $(0.0319)$ & $(0.0247)$ & $(0.0337)$ & $(0.0257)$ \\
EC term CEE & & & 0.0471 & 0.0320 \\
& & & $(0.0776)$ & $(0.0622)$ \\
\hline Effects in EC model & & & & \\
Country FE & $\mathrm{Y}$ & $\mathrm{Y}$ & $\mathrm{Y}$ & $\mathrm{Y}$ \\
Period FE & $\mathrm{N}$ & $\mathrm{Y}$ & $\mathrm{N}$ & $\mathrm{Y}$ \\
\hline
\end{tabular}

Dependent variable is $\Delta \ln y_{i t}$.

Heteroskedasticity robust standard errors in parentheses.

${ }^{* * * *}\left({ }^{* *}\right)\left[{ }^{*}\right]$ indicates significance at the $1 \%(5 \%)[10 \%]$, respectively.

the channels through which finance enhances productivity growth and a more efficient allocation of capital will take time and cannot materialize within shorttime periods. Second, an increase in the capital stock leads to a decrease in per capita output in the short term. This result reflects the short-run nature of the estimated parameters, where an increase in the capital stock reflects higher savings and hence a cut in consumption.

Table 4 presents the results for the error-correction model when we use the regime-specific long-run estimates from the nonlinear model for the construction of the error-correction term. This implies that we compute the deviations to the regime-specific equilibrium and incorporate the resulting disequilibrium vector in the error-correction specification. As is to be expected, the use of regime-specific equilibrium yields a higher estimated speed of adjustment parameter. As a result, also significance increases and the error-correction term is now highly significant at the $1 \%$ level in all specifications.

Besides this, the short-run effects do not change very much when we use regimespecific estimates, regardless of whether we use country-fixed effects only or country- and period-fixed effects. GDP per capita appears to be strongly persistent. If period-fixed effects are included, the coefficient of employment on per capita GDP appears to be positive and significant suggesting that there is a positive impact of employment in the short run. There is a negative short-run impact of the 
TABLE 4. Error-correction model with regime specific long-run elasticities

\begin{tabular}{|c|c|c|c|c|}
\hline \multirow[b]{3}{*}{$\Delta \ln y(-1)$} & \multicolumn{4}{|c|}{ Effects in cointegrating regression } \\
\hline & \multicolumn{2}{|c|}{ Country FE } & \multicolumn{2}{|c|}{ Country and period FE } \\
\hline & $\begin{array}{l}0.2327^{* * *} \\
(0.0741)\end{array}$ & $\begin{array}{l}0.2897^{* * *} \\
(0.0749)\end{array}$ & $\begin{array}{l}0.2161^{\text {**** }} \\
(0.0707)\end{array}$ & $\begin{array}{l}0.3073^{* * *} \\
(0.0717)\end{array}$ \\
\hline$\Delta \ln N(-1)$ & $\begin{array}{c}0.0986 \\
(0.0833)\end{array}$ & $\begin{array}{c}0.1520^{*} \\
(0.0749)\end{array}$ & $\begin{array}{c}0.0974 \\
(0.0839)\end{array}$ & $\begin{array}{l}0.1666^{* *} \\
(0.0742)\end{array}$ \\
\hline$\Delta \ln K(-1)$ & $\begin{array}{c}-0.3952^{* * *} \\
(0.1523)\end{array}$ & $\begin{array}{c}-0.3074^{* *} \\
(0.1359)\end{array}$ & $\begin{array}{c}-0.3752^{* * *} \\
(0.1416)\end{array}$ & $\begin{array}{r}-0.1981 \\
(0.1454)\end{array}$ \\
\hline$\Delta \ln \mathrm{FD}(-1)$ & $\begin{array}{c}0.0106 \\
(0.0082)\end{array}$ & $\begin{array}{c}0.0057 \\
(0.0064)\end{array}$ & $\begin{array}{c}0.0100 \\
(0.0081)\end{array}$ & $\begin{array}{c}0.0065 \\
(0.0066)\end{array}$ \\
\hline EC term & $\begin{array}{c}-0.0825^{* * *} \\
(0.0317)\end{array}$ & $\begin{array}{c}-0.0817^{* * *} \\
(0.0297)\end{array}$ & $\begin{array}{c}-0.0756^{* * *} \\
(0.0206)\end{array}$ & $\begin{array}{c}-0.1103^{* * *} \\
(0.0318)\end{array}$ \\
\hline \multicolumn{5}{|c|}{ Effects in EC model } \\
\hline $\begin{array}{l}\text { Country FE } \\
\text { Period FE }\end{array}$ & $\begin{array}{l}\mathrm{Y} \\
\mathrm{N}\end{array}$ & $\begin{array}{l}\mathrm{Y} \\
\mathrm{Y}\end{array}$ & $\begin{array}{l}\mathrm{Y} \\
\mathrm{N}\end{array}$ & $\begin{array}{l}\mathrm{Y} \\
\mathrm{Y}\end{array}$ \\
\hline
\end{tabular}

capital stock in all models but the model with country- and period-fixed effects in the cointegrating and error-correction specification. Finally, we do not find a short-run effect of financial depth on growth. Overall, the results confirm the hypothesis of a differing impact of the capital stock, employment, and financial depth on per capita GDP in the short and in the long run. They also underline the importance of accounting for cointegration in the analysis of financial depth on per capita GDP.

One central result of our error-correction model is the highly significant coefficient of the error-correction term. Together with the results of the long-run specification, the results of the error-correction model demonstrate the importance of disentangling short run from long-run effects in the analysis of the financegrowth nexus. Financial depth does have a long term but no short-term impact on the economy, suggesting that our theoretical analysis in Section 2 based only on the long-run impact of finance on growth captures well the nature of the finance-growth relation. The results show that the benefits of financial services in enabling and facilitating economic activity do not arise from a financial sector being a growth sector in itself (see Beck, 2013). The positive or negative impact (depending on the achieved level of financial depth) realizes in the long run, and whenever there is a deviation from equilibrium, e.g., whenever per capita GDP is 
too high given a certain level of capital stock, employment, and financial depth, there is an automatic adjustment to a predetermined long-term equilibrium level.

\section{CONCLUSION}

The nature of the growth and finance nexus has been extensively discussed but the results are mixed; the most recent empirical evidence suggests that this relation may be nonmonotonic and in particular bell-shaped. This paper reexamines the relationship between economic growth and finance from a theoretical and an empirical perspective. The theoretical model is given by the simplest possible finance-extended model of endogenous growth. This consists of an AK-type framework in which financial development, through its effects on financial intermediation, affects both productivity and the amount of resources diverted from capital accumulation, which determines the level of financial depth. Provided that (realistically) financial development affects productivity positively and crowding out negatively, then the relation between growth and financial depth is likely to be nonmonotonic (and in particular it may be bell-shaped) in line with empirical evidence. This result suggests that the observed empirical regularities in the nature of the finance and growth nexus arise almost naturally, as long as we take into account the implications of financial development on economic activities.

We validate our theoretical conclusions by developing an empirical approach allowing to estimate whether there is a nonlinear relationship between financial depth and output, and thus economic growth. Since we find strong indication for nonstationarity in the time series included and that cointegration is present among the variables, we consider the theoretical model as the long-run equilibrium situation of a cointegrated panel and set up a model that allows to distinguish between short run and long-run effects of financial depth on growth. Specifically, we estimate a panel error-correction model in a two-step procedure, where the first step involves the estimation of the cointegrating vector, yielding the longrun elasticities of per capita GDP with employment, the capital stock and the financial depth indicator. We find that there appears to be a positive impact of finance on growth in the long run as long as we assume a homogeneous long-run equilibrium for all countries in the sample. Allowing for a heterogeneous long-run relationship and estimating the cointegrated regression with thresholds in financial depth, reveals that the assumption of a homogeneous long-run relationship cannot hold. In all models, which allow for a group-specific effect of finance on GDP, we find that while at low levels of financial depth, finance has a positive impact on GDP, at higher levels of financial depth, finance loses its positive impact on GDP and the effect eventually becomes significantly negative for countries with a financial depth level above a threshold of private credit to GDP of $68.5 \%$. We use the estimates of the long-run elasticities to obtain the error-correction term for both the homogeneous and regime-specific cointegrating vector, where for the latter case the error-correction term captures deviations to the regime specific long-run equilibrium. The results demonstrate the relevance of long-run stationary 
equilibria between per capita GDP, employment, the capital stock, and financial depth. Further, they support our approach aimed at distinguishing between longrun and short-run effects. Altogether, the empirical analysis confirms our main theoretical results about the existence of a nonmonotonic long-run relationship between growth and financial depth.

\section{NOTES}

1. In spite of the existence of a positive impact of financial deepening on economic growth, the banking and currency crisis literatures view credit growth itself as one of the most reliable predictors of a financial crisis [Loayza and Ranciere (2006)].

2. King and Levine (1993a) are among the first to show how a more developed financial system (financial intermediaries) can contribute, through better screening and monitoring activities, to raise the rate of technological progress by identifying those entrepreneurs most likely to effectively give rise to innovation by discovering new goods or new production processes.

3. This absorption of resources by the financial sector can primarily be interpreted as a reward for services supplied, but it may also reflect the inefficiencies of financial intermediaries [Pagano (1993)].

\section{REFERENCES}

Allen, F. (1990) The market for information and the origin of financial intermediaries. Journal of Financial Intermediation 1, 3-30.

Allen, F., A. Babus, and E. Carletti (2009) Financial crises: Theory and evidence. Annual Review of Financial Economics 1, 97-116.

Allen, F., E. Carletti, J. Qian, and P. Valenzuela (2014) Does finance accelerate or retard growth? Theory and evidence. In F. Allen, J. R. Behrman, N. Birdsall, S. Fardoust, D Rodrik, A. Steer, and A. Subramanian (eds.), Towards a Better Global Economy: Policy Implications for Citizens Worldwide, pp. 289-380. Oxford: Oxford University Press.

Arcand, J. L., E. Berkes, and U. Panizza (2015) Too much finance? Journal of Economic Growth 20, $105-148$.

Beck, T. (2012) Finance and growth—Lessons from the literature and the recent crisis, LSE Growth Commission.

Beck, T. (2013) Finance, growth and fragility: The role of government. International Journal of Banking, Accounting and Finance 5, 49-77.

Beck, T., R. Levine, and N. Loayza (2000) Finance and the sources of growth. Journal of Financial Economics 58, 261-300.

Benhabib, J. and M. M. Spiegel (2000) The role of financial development in growth and investment. Journal of Economic Growth 5, 341-360.

Berlemann, M. and J.-E. Wesselhoeft (2014) Estimating aggregate capital stocks using the perpetual inventory method. A survey of previous implementations and new empirical evidence for 103 countries. Review of Economics 65, 1-34.

Boyd, J. H. and E. C. Prescott (1986) Financial intermediary-coalitions. Journal of Economic Theory 38, 211-232.

Breitung, J. (2005) A parametric approach to the estimation of cointegration vectors in panel data. Econometric Reviews 24, 151-173.

Bucci, A. and S. Marsiglio (2018) Financial Development and Economic Growth: Long Run Equilibrium and Transitional Dynamics, Scottish Journal of Political Economy, forthcoming, DOI: 10.1111/sjpe.12182

Cecchetti, S. G. and E. Kharroubi (2012) Reassessing the Impact of Finance on Growth. BIS working papers 381/2012. 
Cihak, M., A. Demirguc-Kunt, E. Feyen, and R. Levine (2012) Benchmarking Financial Systems Around the World. Policy Research working paper 6175, Washington, DC: World Bank.

Christopoulos, D. K. and E. G. Tsionas (2004) Financial development and economic growth: Evidence from panel unit root and cointegration tests. Journal of Development Economics 73, 55-74.

De Gregorio, J. (1996) Borrowing constraints, human capital accumulation, and growth. Journal of Monetary Economics 37, 49-71.

De Gregorio, J. and S.-J. Kim (2000) Credit markets with differences in abilities: Education, distribution and growth. International Economic Review 41, 579-607.

Greenwood, J. and B. Jovanovic (1990) Financial development, growth, and the distribution of income. Journal of Political Economy 98, 1076-1108.

Im, K. S., M. H. Pesaran, and Y. Shin (2003) Testing for unit roots in heterogeneous panels. Journal of Econometrics 115, 53-74.

King, R. G. and R. Levine (1993a) Finance and growth: Schumpeter might be right. Quarterly Journal of Economics 108, 717-737.

King, R. G. and R. Levine (1993b) Finance, entrepreneurship and growth: theory and evidence. Journal of Monetary Economics 32, 513-542.

Law, S. H. and N. Singh (2014) Does too much finance harm economic growth?. Journal of Banking \& Finance 41, 36-44.

Levin, A., C.-F. Lin, and C.-S. James Chu (2002) Unit root tests in panel data: Asymptotic and finite-sample properties. Journal of Econometrics 108, 1-24.

Levine, R. (2005) Finance and growth: Theory and evidence. In P. Aghion and S. N. Durlauf (eds.), Handbook of Economic Growth, pp. 866-934. Amsterdam: Elsevier North-Holland.

Levine, R., N. Loayza, and T. Beck (2000) Financial intermediation and growth: Causality and causes. Journal of Monetary Economics 46, 31-77.

Levine, R. and S. Zervos (1998) Stock markets, banks, and economic growth. American Economic Review 88, 537-558.

Loayza, N. and R. Ranciere (2006) Financial development, financial fragility, and growth. Journal of Money, Credit and Banking 38, 1051-1076.

Morales, M. F. (2003) Financial intermediation in a model of growth through creative destruction. Macroeconomic Dynamics 7, 363-393.

Pagano, M. (1993) Financial markets and growth: An overview. European Economic Review 37, 613-622.

Pedroni, P. (1999) Critical values for cointegration tests in heterogeneous panels with multiple regressors. Oxford Bulletin of Economics and Statistics 61, 653-670.

Pedroni, P. (2004) Panel cointegration: Asymptotic and finite sample properties of pooled time series tests with an application to the PPP hypothesis. Econometric Theory 20, 597-625.

Saikkonen, P. (1991) Asymptotically efficient estimation of cointegration regressions. Econometric Theory 7, 1-21.

Trew, A. (2008) Efficiency, depth and growth: Quantitative implications of finance and growth theory. Journal of Macroeconomics 30, 1550-1568.

Trew, A. (2014) Finance and balanced growth. Macroeconomic Dynamics 18, 883-898.

Wagner, M. and J. Hlouskova (2010) The performance of panel cointegration methods: Results from a large scale simulation study. Econometric Reviews 29, 182-223.

Wu, J. L., H. Hou, and S. Y. Cheng (2010) The dynamic impacts of financial institutions on economic growth: Evidence from the European Union. Journal of Macroeconomics 32, 879-891. 


\section{APPENDIX A: COUNTRIES INCLUDED IN THE DATASET}

Australia, Austria, Bulgaria, Chile, Colombia, Costa Rica, Denmark, Dominican Republic, Ecuador, Egypt, El Salvador, Finland, France, Germany, Greece, Hong Kong, Hungary, Iceland, Israel, Italy, Japan, Lithuania, Mexico, Netherlands, New Zealand, Panama, Paraguay, Peru, Philippines, Poland, Portugal, Russian Federation, Singapore, Slovenia, South Africa, Spain, Sri Lanka, Sweden, Switzerland, Turkey, Ukraine, United Kingdom, United States, and Venezuela.

\section{APPENDIX B: UNIT ROOT TESTS}

TABLE B.1. Panel unit root tests

\begin{tabular}{lccccc}
\hline & \multicolumn{2}{c}{ Levels } & & \multicolumn{2}{c}{ First differences } \\
\cline { 2 - 3 } & Statistic & $p$-value & & Statistic & $p$-value \\
\hline GDP & & & & \\
Levin, Lin \& Chu $t^{*}$ & $-3.9141^{* * *}$ & 0.0000 & & $-9.4416^{* * *}$ & 0.0000 \\
Breitung $t$-stat & 3.2404 & 0.9994 & & $-3.1502^{* * *}$ & 0.0008 \\
Im, Pesaran and Shin $W$-stat & 0.9234 & 0.8221 & & $-4.7744^{* * *}$ & 0.0000 \\
Employment & & & & \\
Levin, Lin \& Chu $t^{*}$ & $-3.6278^{* * *}$ & 0.0001 & & $-9.4528^{* * *}$ & 0.0000 \\
Breitung $t$-stat & 2.5980 & 0.9953 & & $-3.7687^{* * *}$ & 0.0001 \\
Im, Pesaran and Shin $W$-stat & 0.8013 & 0.7885 & & $-4.3185^{* * *}$ & 0.0000 \\
Capital stock & & & & \\
Levin, Lin \& Chu $t^{*}$ & $-4.51368^{* * *}$ & 0.0000 & & $-7.83753^{* * *}$ & 0.0000 \\
Im, Pesaran and Shin $W$-stat & 1.00403 & 0.8423 & & $-3.20018^{* * *}$ & 0.0007 \\
Private credit & & & & \\
Levin, Lin and Chu $t^{*}$ & $-4.7863^{* * *}$ & 0.0000 & & $-11.7689^{* * *}$ & 0.0000 \\
Breitung $t$-stat & 4.2570 & 1.0000 & $-1.6862^{* *}$ & 0.0459 \\
Im, Pesaran and Shin $W$-stat & 0.3394 & 0.6328 & $-6.0924^{* * *}$ & 0.0000 \\
\hline
\end{tabular}

The Augmented Dickey Fuller regressions of the above tests include a constant and a trend for GDP, employment, and private credit. We include 1 lag to account for autocorrelation. The regressions of the test for the capital stock include a constant and country specific number of lags. 


\section{APPENDIX C: ROBUSTNESS CHECKS}

In our empirical analysis thus far, we have focused on credit to the private sector as an indicator of financial depth, since this is the most commonly used measure in extant empirical studies. However, the empirical literature on the finance and growth nexus also suggests a couple of other indicators that capture different roles of financial activities on the economy. We now include a set of those alternative indicators, reported in Table C.1, to show that our qualitative results on the long-run growth and finance relation hold true even in more general settings. The panel unit root and cointegration tests of the indicators included here, suggest that the series are $I(1)$ and cointegrated with per capita GDP, employment, and the capital stock.

Table C.1 shows the estimated long-run elasticities for different measures of financial depth. The first set of elasticities are those found earlier in our baseline analysis from the threshold model, with country and period with effects (see Table 2), by relying on credit to the private sector. We then include domestic credit provided by the banking sector as a percentage of GDP in the analysis, which is a similar but a broader indicator than credit to the private sector. Using such a broader measure of domestic credit, we find that there is a positive relationship of financial depth on GDP in the lower two regimes and but a negative relationship for the the regime of high domestic credit provided by the banking sector.

TABLE C.1. Long-run relationship: Threshold model with different proxies for financial depth

\begin{tabular}{|c|c|c|c|c|c|c|}
\hline $\ln N$ & $\ln K$ & $\begin{array}{c}\ln \text { FD } \\
\text { Regime } 1\end{array}$ & $\begin{array}{c}\ln \mathrm{FD} \\
\text { Regime } 2\end{array}$ & $\begin{array}{c}\ln \text { FD } \\
\text { Regime } 3\end{array}$ & $R^{2}$ & Obs \\
\hline \multicolumn{7}{|c|}{ Domestic credit to the private sector as $\%$ of GDP } \\
\hline $\begin{array}{c}-0.0844 \\
(0.0788)\end{array}$ & $\begin{array}{l}0.3133^{* * *} \\
(0.0609)\end{array}$ & $\begin{array}{l}0.2189^{* * *} \\
(0.0192)\end{array}$ & $\begin{array}{l}0.0700^{* * *} \\
(0.0192)\end{array}$ & $\begin{array}{c}-0.0698^{* * *} \\
(0.0192)\end{array}$ & 0.999 & 490 \\
\hline $\begin{array}{c}-0.1937^{* *} \\
(0.0786)\end{array}$ & $\begin{array}{l}\text { Domestic credi } \\
0.1985^{* * *} \\
(0.0631)\end{array}$ & $\begin{array}{l}\text { provided by th } \\
0.0844^{* * *} \\
(0.0298)\end{array}$ & $\begin{array}{c}\text { e banking sectc } \\
0.1838^{* * *} \\
(0.0349)\end{array}$ & $\begin{array}{c}\text { or as \% of GDP } \\
-0.0650^{* * *} \\
(0.0190)\end{array}$ & 0.998 & 503 \\
\hline $\begin{array}{l}0.33700^{* * * *} \\
(0.0747)\end{array}$ & $\begin{array}{l}\text { Outstanding } \\
0.44711^{* * *} \\
(0.0558)\end{array}$ & $\begin{array}{l}0.02071^{* * *} \\
(0.0059)\end{array}$ & $\begin{array}{l}\text { debt securities } \\
-0.08034^{* * *} \\
(0.0122)\end{array}$ & $\begin{array}{l}\text { s to GDP }(\%) \\
-0.02782^{* * *} \\
(0.0096)\end{array}$ & 0.998 & 337 \\
\hline $\begin{array}{c}-0.091632 \\
(0.0918)\end{array}$ & $\begin{array}{l}\text { Outstanding in } \\
0.366464^{* * *} \\
(0.0720)\end{array}$ & $\begin{array}{c}\text { rnational priv } \\
0.017378^{* *} \\
(0.0069)\end{array}$ & $\begin{array}{l}\text { ate debt securiti } \\
0.138602^{* * *} \\
(0.0168)\end{array}$ & $\begin{array}{l}\text { ies to GDP }(\%) \\
-0.022461^{* * *} \\
(0.0080)\end{array}$ & 0.998 & 405 \\
\hline $\begin{array}{l}0.153195 \\
(0.1530)\end{array}$ & $\begin{array}{c}\text { mployment sha } \\
0.504887^{* * *} \\
(0.0683)\end{array}$ & $\begin{array}{c}\text { of financial se } \\
0.068879 \\
(0.0703)\end{array}$ & $\begin{array}{c}\text { rvices industry } \\
0.712485^{* * *} \\
(0.1268)\end{array}$ & $\begin{array}{l}\text { in total econon } \\
-0.23932^{* * *} \\
(0.0691)\end{array}$ & 0.997 & 145 \\
\hline
\end{tabular}

Dependent variable is $\ln y_{i t}$, country- and period-fixed effects are included in all specifications. Heteroskedasticity robust standard errors in parentheses.

${ }^{* * * *}\left({ }^{* *}\right)\left[{ }^{*}\right]$ indicates significance at the $1 \%(5 \%)[10 \%]$, respectively. 
Turning to outstanding domestic private debt securities to GDP, which is an even broader measure that captures all issuers except governments, we find again an inverse $U$-shaped relationship. In contrast to private credit, finance is already negatively associated with GDP in the second regime and this negative association becomes stronger as the level of finance increases. This result to some extent supports the findings by Beck (2013), suggesting that for growth what really matters is "who gets the credit." For the same measure covering placement on international markets, we obtain a positive association for the first two regimes but a negative effect in the third regime. To summarize the results of the different measures on credit and debt, we find that finance and growth are positively linked at lower levels of financial depth, but this link eventually turns into a negative one at higher levels of depth.

We then employ the financial sector's share in total employment as an alternative measure of financial depth, consistently with Cecchetti and Kharroubi (2012) who suggest that such an indicator may quantify financial activities through an input measure rather than the conventionally used output measure. We use the data from the OECD Structural Analysis database, which unfortunately reduces the sample size substantially to eleven countries. The result of the analysis however shows once again, the presence of nonmonotonic effects: financial depth does not not affect in any way the economy at lower level, while it does so first positively and then negatively as the level of depth increases.

\section{C.1. Alternative Formulation Based on Growth Rates}

An alternative specification for the empirical model considered in the body of the paper can be obtained by setting the model to focus on the effects of financial depth on the growth rate of GDP, calculated on either a 5 year or a 4 year average. This alternative formulation reads as follows:

$$
\gamma_{i t}=a+\alpha \ln K_{i t}+\beta \ln N_{i t}+\eta \ln \mathrm{FD}_{i t}+\epsilon_{i t},
$$

which has the advantage to be written directly with the growth rate as the dependent variable and thus to be more consistent with our theoretical model from Section 2. As it was reasonable to expect, also by focusing directly on the effects of financial depth on growth we still find the existence of an inverted $U$-shaped relationship between finance and growth: financial depth has a positive impact on growth in the lower regime, this effect

TABLE C.2. Growth and financial depth

\begin{tabular}{|c|c|c|c|c|c|c|}
\hline $\ln N$ & $\ln K$ & $\begin{array}{c}\ln \text { FD } \\
\text { Regime } 1\end{array}$ & $\begin{array}{c}\text { ln FD } \\
\text { Regime } 2\end{array}$ & $\begin{array}{c}\ln \text { FD } \\
\text { Regime } 3\end{array}$ & $R^{2}$ & Obs \\
\hline \multicolumn{7}{|c|}{ 5-year averages } \\
\hline $\begin{array}{l}0.77379^{* * *} \\
(0.23852)\end{array}$ & $\begin{array}{r}-0.347305^{*} \\
(0.187375)\end{array}$ & $\begin{array}{l}0.427058^{* * *} \\
(0.125988)\end{array}$ & $\begin{array}{c}0.056096 \\
(0.050831)\end{array}$ & $\begin{array}{c}-0.141707^{* *} \\
(0.056715)\end{array}$ & 0.663 & 503 \\
\hline \multicolumn{7}{|c|}{ 4-year averages } \\
\hline $\begin{array}{l}0.756094^{* * *} \\
(0.281262)\end{array}$ & $\begin{array}{r}-0.245617 \\
(0.193017)\end{array}$ & $\begin{array}{c}0.257661^{* *} \\
(0.117278)\end{array}$ & $\begin{array}{c}-0.017692 \\
(0.059836)\end{array}$ & $\begin{array}{c}-0.167481^{* * *} \\
(0.063308)\end{array}$ & 0.660 & 503 \\
\hline
\end{tabular}

Heteroskedasticity robust standard errors in parentheses.

${ }^{* * *}\left({ }^{* *}\right)\left[{ }^{*}\right]$ indicates significance at the $1 \%(5 \%)[10 \%]$, respectively. 
vanishes as the level of depth increases and finally, after a certain point the effect becomes negative. These results clearly show once again the robustness of our baseline model to different specifications.

Together with the results from the error-correction model, this tells us a lot about the interplay between finance and growth. There exists a long-run relationship between financial depth and income: such a long-run relationship is regime specific and there exists a correction to the long-run equilibrium whenever the economy departs from it. The inverted $U$-shaped relationship between finance and income shows up in the first differences (i.e., in growth rates) and therefore also in the error-correction model; these dynamic effects impact on long-run growth (measured by the average growth rate over several years) as given in (C.1). As expected and as shown by the results in Table C.2, the inverted $U$-shaped relationship between financial depth and growth found in our baseline specification is present in the growth rates as well. 